\title{
Endogenous Homer Proteins Regulate Metabotropic Glutamate Receptor Signaling in Neurons
}

\author{
Paul J. Kammermeier \\ Department of Pharmacology and Physiology, University of Rochester Medical Center, Rochester, New York 14642
}

\begin{abstract}
Group I metabotropic glutamate receptors (mGluR1 and mGluR5) are important neuronal mediators of postsynaptic signaling that influence synaptic strength, plasticity, and other factors. Regulation of group I mGluR localization and function by Homer proteins appears to be a viable means for neurons to fine-tune these processes. The presence of different Homer isoforms can act as a switch to reprioritize mGluR1 and mGluR5 signaling at the point of $\mathrm{IP}_{3}$ receptor activation by promoting or reducing activation of specific downstream effectors. Furthermore, these Homer-dependent effects on mGluR signaling may mechanistically underlie many of the long-term changes in neuronal function associated with changes in Homer protein expression described in the recent literature. However, most studies focusing on mGluR regulation by Homer proteins used relatively long-term overexpression. Thus, a definitive demonstration of mGluR1/5 signal regulation by natively expressed Homer proteins has been elusive. I examined the ability of endogenous Homer 1a to alter mGluR signaling in rat sympathetic neurons and hippocampal autapses using pituitary adenylate cyclase activating peptide (PACAP) to induce native Homer la expression. In sympathetic neurons, both Homer la overexpression and PACAP treatment reversed the decrease in mGluR1-mediated calcium current modulation associated with Homer $2 \mathrm{~b}$ expression. In hippocampal autapses, PACAP treatment uncoupled postsynaptic mGluR5 from EPSC inhibition, similar to the effect of Homer la overexpression. In both cases, RNA silencing of Homer 1a but not control RNA interference treatment prevented the PACAP effect, suggesting that it resulted specifically from native Homer la expression.
\end{abstract}

Key words: metabotropic glutamate receptor; calcium channel; autapse; modulation; synapse; G-protein; $\mathrm{IP}_{3}$ receptor

\section{Introduction}

Metabotropic glutamate receptors (mGluRs) are members of family 3 of the G-protein-coupled receptor superfamily and reside in nearly every region of the brain (Ozawa et al., 1998). Group I mGluRs (mGluR1 and mGluR5) are unique among mGluRs in their coupling to the $\mathrm{G} \alpha_{\mathrm{q}}$-protein/phospholipase C cascade and often express near the postsynaptic density (Schoepp, 2001). Homer is a family of postsynaptic scaffolding proteins that interact with several binding partners, including group I mGluRs (Brakeman et al., 1997), $\mathrm{IP}_{3}$ receptors (Tu et al., 1998; Xiao et al., 1998), ryanodine receptors (Feng et al., 2002), TRPC channels (Yuan et al., 2003), the postsynaptic protein Shank (Tu et al., 1999), and others (Ehrengruber et al., 2004). With respect to mGluRs, Homer proteins exert effects on both localization and signaling (Thomas, 2002).

A model to explain the functional regulation of mGluRs by Homer proteins suggests that "long" Homer proteins (Homer $1 b, 1 c, 2$, and 3) act as scaffolds to localize mGluRs in close proximity to the $\mathrm{IP}_{3}$ receptor near the postsynaptic density as part of a

Received March 21, 2008; revised July 7, 2008; accepted July 12, 2008.

I thank D. Krenitsky for valuable technical assistance, P. F. Worley for providing the original Homer clones, and A. V. Smrcka, D. I. Yule, R. T. Dirksen, and N. A. Lambert for helpful discussions.

Correspondence should be addressed to Paul J. Kammermeier, 601 Elmwood Avenue, Box 711, Department of Pharmacology and Physiology, University of Rochester Medical Center, Rochester, NY 14642. E-mail: paul_kammermeier@urmc.rochester.edu.

DOI:10.1523/JNEUROSCI.1830-08.2008

Copyright $\odot 2008$ Society for Neuroscience $\quad$ 0270-6474/08/288560-08\$15.00/0 discreet signaling microdomain. "Short" Homers (Homer 1a and Ania-3), which bind mGluRs but do not aggregate (and which exhibit regulated expression), appear to act as natural dominant negatives. Consequently, the presence of long versus short Homer proteins can act as a molecular switch to reprioritize group I mGluR signaling, with effectors downstream of $\mathrm{IP}_{3}$ receptor activation being favored in the presence of long Homers and those independent of $\mathrm{IP}_{3}$ receptor activity being favored when Homer la predominates or when Homer proteins are absent. Thus, predominance of long Homers can uncouple mGluRs from the modulation of plasma membrane $\mathrm{N}$-type calcium and M-type potassium channels (Kammermeier et al., 2000), which are inhibited by association with G-protein (Herlitze et al., 1996; Ikeda, 1996) and by PIP 2 depletion (Suh and Hille, 2002), respectively. Likewise, predominance of Homer 1a favors coupling to these effectors but uncouples mGluRs from acute inhibition of AMPA receptors and from stimulation of intracellular calcium signaling (Kammermeier and Worley, 2007), both of which require $\mathrm{IP}_{3}$ receptor activity.

However, the model described above relies almost exclusively on data from relatively long-term studies using overexpression of Homer proteins. To date, there has been no demonstration of group I mGluR signaling resulting from changes in the levels of natively expressed Homer proteins.

In this study, group I mGluR signaling was examined in two separate neuronal systems in which endogenous Homer 1a was caused to be upregulated by application of pituitary adenylate 
cyclase activating peptide (PACAP), an agonist of the PAC1 receptor, a $\mathrm{G} \alpha_{\mathrm{s}}$-coupled receptor known to stimulate Homer 1a expression in these systems, without detectably altering long Homer protein expression levels (Nielsen et al., 2002; Girard et al., 2004). Dependence of the observed changes on Homer 1a expression was tested using RNA interference against Homer 1. The results demonstrate that native Homer 1a, even at relatively modest levels, is a potent and effective regulator of mGluR signaling.

\section{Materials and Methods}

Electrophysiology and data analysis. Patch pipettes were made from 8250 glass (Garner Glass) and had resistances of 1-6 M . Series resistances were 2-8 M $\Omega$ before electronic compensation, which was $\geq 80 \%$. Ruptured patch whole-cell recordings of EPSCs and outside-out patch recordings were made with a EPC-7 patch-clamp amplifier (HEKA Elektronik). Voltage protocol generation and data acquisition were performed using custom software (generously donated by Stephen R. Ikeda, National Institute on Alcohol Abuse and Alcoholism, Rockville, MD) on a Macintosh G4 series computer (Apple Computers) with an ITC16 data acquisition board (InstruTECH). Currents were low-pass filtered at $3 \mathrm{kHz}$ using filter in the patch-clamp amplifier, digitized at 2-5 $\mathrm{kHz}$, and stored on the computer for later analysis. Experiments were performed at $21-24^{\circ} \mathrm{C}$ (room temperature). Data analysis was performed using Igor Pro software (Wavemetrics). Statistical analysis was performed using InStat software (GraphPad Software). Statistical significance ( $p \leq 0.05$; indicated by ${ }^{*}$ in each figure) was determined using ANOVA tests (see Figs. 1, 2, 4) or Student's $t$ test (see Figs. 5, 6).

The external (bath) solution for calcium current recording contained the following (in mM): 155 Tris hydroxymethyl aminomethane, 20 HEPES, 10 glucose, $10 \mathrm{CaCl}_{2}$, and 0.0003 tetrodotoxin, $\mathrm{pH}$ 7.4. The internal (pipette) solution contained the following (in $\mathrm{mm}$ ): 120 $\mathrm{N}$-methyl-D-glucamine methanesulfonate, 20 tetraethylammonium, 11 EGTA, 10 HEPES, 10 sucrose, $1 \mathrm{CaCl}_{2}, 4 \mathrm{MgATP}, 0.3 \mathrm{Na}_{2} \mathrm{GTP}$, and 14 Tris creatine phosphate, pH 7.2. L-Glutamate at $100 \mu \mathrm{M}$ (Sigma-Aldrich) was used as the agonist for mGluR1. For autaptic EPSC recording, the bath solution contained the following (in $\mathrm{mm}$ ): $140 \mathrm{NaCl}, 5.4 \mathrm{KCl}, 10$ HEPES, $1.2 \mathrm{MgCl}_{2}, 1.2 \mathrm{CaCl}_{2}$, and 15 glucose. The internal (pipette) solution contained the following (in mM): $130 \mathrm{KCl}, 1.1 \mathrm{EGTA}, 10 \mathrm{HEPES}$, $0.1 \mathrm{CaCl}_{2}, 4 \mathrm{MgATP}$, and $0.1 \mathrm{NaGTP}, \mathrm{pH}$ 7.2. (RS)-3,5-dihydroxyphenylglycine (DHPG) at $50 \mu \mathrm{M}$ (Tocris Bioscience) was used as an agonist for mGluR5 in these neurons. PACAP (Tocris Bioscience) was added at $200 \mathrm{~nm}$ directly to the media of both superior cervical ganglion (SCG) and hippocampal neurons for $3-5 \mathrm{~h}$ before patch-clamp experiments were performed.

Acutely applied drugs and control solutions were applied to cells using a custom, gravity-driven perfusion system positioned $\sim 100 \mu \mathrm{m}$ from the cell that allowed rapid solution exchange $(\leq 250 \mathrm{~ms})$. The degree of EPSC inhibition was calculated as the maximal inhibition of the current in the presence of drug compared with the last current measurement before application of the drug, measured at the time of EPSC peak. Calcium current inhibition in each case is reported as percentage inhibition of the current recorded at $+10 \mathrm{mV}$, measured at $10 \mathrm{~ms}$ from the start of the step, taken as the maximal inhibition in the presence of the drug compared with the last measurement taken before drug application. A triplepulse protocol was used for all current time course measurements to evaluate the relative contributions of the $\mathrm{G}_{\mathrm{i} / \mathrm{o}}$ and $\mathrm{G}_{\mathrm{q}}$-mediated calcium current inhibitory pathways, which manifest as voltage dependent and voltage independent, respectively. See supplemental Figure 1 (available at www.jneurosci.org as supplemental material) for currents from the full protocols. This protocol allows simultaneous assessment of channel inhibition through both pathways because only inhibition via the G- $\beta \gamma$ pathway is relieved by the depolarizing step to $+80 \mathrm{mV}$ (Ikeda, 1996). As reported by Kammermeier et al. (2000), the relative contribution of the $\mathrm{G}_{\mathrm{q}^{-}}$and $\mathrm{G}$-protein pathways was unaltered when inhibition was enhanced or reduced by various Homer proteins, indicating that both are equally affected by Homer protein association (data not shown). Therefore, to simplify interpretation, only the currents from the initial test pulse to $+10 \mathrm{mV}$ are shown in Figures 1, 2, and 4 and discussed in the text.

SCG cultures. A detailed description of the cell isolation protocol can be found in previous studies (Ikeda, 1997). Animal protocols were approved by the Committee on Animal Resources of the University of Rochester. Briefly, SCGs were removed from adult male Wistar rats (175-225 g) after $\mathrm{CO}_{2}$ overdose and decapitation and were incubated in Earle's balanced salt solution (Invitrogen) containing $0.55 \mathrm{mg} / \mathrm{ml}$ trypsin (Worthington Biochemicals) and $0.7 \mathrm{mg} / \mathrm{ml}$ collagenase D (Roche Diagnostics) for $1 \mathrm{~h}$ at $35^{\circ} \mathrm{C}$. Cells were then transferred to minimum essential medium (MEM) (Invitrogen), plated on poly-L-lysine (Sigma)-coated 35 $\mathrm{mm}$ polystyrene tissue culture dishes and incubated (95\% air and 5\% $\mathrm{CO}_{2} ; 100 \%$ humidity) at $37^{\circ} \mathrm{C}$ before DNA injection. After injection, cells were incubated overnight at $37^{\circ} \mathrm{C}$, and patch-clamp or immunofluorescence experiments were performed the following day.

Hippocampal cultures. Hippocampi were removed from postnatal days $0-2$ neonatal Wistar rats, cut into small pieces, and incubated for $1 \mathrm{~h}$ in 25-35 U/ml papain (Worthington Biochemicals) in serum-free MEM (Invitrogen). After enzymatic dissociation, the tissue was washed three times with "growth medium": MEM supplemented with 5\% FBS, penicillin/streptomycin, $1 \mathrm{~mm}$ pyruvate, $0.6 \%$ glucose, $2 \%$ B-27 supplement, $0.1 \%$ mito-serum extender, $10 \mu \mathrm{M}$ uridine, and $2.5 \mu \mathrm{M} 5$-fluorodeoxyuridine (Sigma) to inhibit glial proliferation. Tissue was then triturated in growth medium and centrifuged $(120 \times g, 5 \mathrm{~min})$, resuspended in growth medium, and plated at 20,000-50,000 cells $/ \mathrm{cm}$. Autaptic cultures were plated on $35 \mathrm{~mm}$ plastic tissue culture dishes coated with a thin layer of $0.15 \%$ agarose and sprayed with a 1:1 mixture of rat tail collagen (BD Biosciences) and poly-D-lysine (Sigma) to form small $(50-200 \mu \mathrm{m})$ "islands" of substrate. Standard cultures were plated on poly-L-lysine (Sigma)-coated $35 \mathrm{~mm}$ culture dishes (Corning Life Sciences) or on poly-L-lysine-coated glass coverslips (for calcium imaging experiments). In all cases, neurons were used for experiments after 7-10 d in culture.

Transfection/cDNA injection, plasmids, and small interference RNA constructs. Injection of cDNA in SCG neurons was performed with an Eppendorf 5247 microinjector and InjectMan NI 2 micromanipulator 4-6 $\mathrm{h}$ after cell isolation (Ikeda, 1997). Injection electrodes were made with a Sutter Instruments P-97 horizontal electrode puller using thin-walled, borosilicate glass (World Precision Instruments). Plasmids were stored at $-20^{\circ} \mathrm{C}$ as a $1 \mu \mathrm{g} / \mu \mathrm{l}$ stock solution in TE buffer $(10 \mathrm{~mm}$ Tris and $1 \mathrm{~mm}$ EDTA, pH 8). mGluR1 constructs were injected at $50-100 \mathrm{ng} / \mu \mathrm{l}$, as indicated (pCDNA3. ${ }^{+}$; Invitrogen). Homer $2 \mathrm{~b}$ cDNA (in the pRK5 vector, originally obtained from Paul F. Worley, Johns Hopkins University, Baltimore, MD) was injected at $10-30 \mathrm{ng} / \mu \mathrm{l}$, at levels determined to yield submaximal uncoupling from calcium current modulation (as described in Results). Homer la cDNA (see Fig. 1) was injected at 100 $\mathrm{ng} / \mu \mathrm{l}$. Both the specific H1-short hairpin RNA (shRNA) construct and the control shRNA (Con-shRNA) plasmid were injected at $50 \mathrm{ng} / \mu \mathrm{l}$ and constructed in the pSilencer 3.0-H1 vector (Ambion). These were designed to make RNA hairpins from the sense sequences GCTCAAAGGCAATAATAAA (H1-shRNA) and ATTCAGCAATCATGATTAA (Con-shRNA). Double-stranded small interfering RNAs (siRNAs) transfected in hippocampal neurons corresponded to the same sequences. In addition, a commercially available, cyanine 3-tagged control siRNA (Ambion) was also used for transfection, as described in the text. Each siRNA was transfected into hippocampal neurons with the Metafectene reagent (Biontex Laboratories) using $500 \mathrm{ng}$ per $35 \mathrm{~mm}$ dish. All SCG neurons were coinjected with enhanced green fluorescent protein cDNA $(0.005 \mu \mathrm{g} / \mu \mathrm{l}$; pEGFPN1; BD Biosciences Clontech) to facilitate identification of successfully injected cells. Plasmids were propagated in the Top10 Escherichia coli strain (Invitrogen), and midipreps were prepared using Qiagen anion exchange columns.

\section{Results \\ Rescue of mGluR1 calcium channel modulation by Homer la overexpression}

To examine group I mGluR-mediated modulation of N-type calcium channels, rat sympathetic neurons from the rat SCG were used because of the abundance and relative purity of N-channels 
in these cells and the well described ion channel modulatory mechanisms (Hille, 1994). SCG neurons are advantageous in that they represent an authentic neuronal system with a null-mGluR background (Ikeda et al., 1995; Kammermeier and Ikeda, 1999). Thus, this system can be used to study signaling of an expressed mGluR (transfected by intranuclear cDNA injection) in isolation.

In the SCG system, coexpression of the long Homer protein Homer $2 \mathrm{~b}$ potently uncouples mGluR1 and mGluR5 from $\mathrm{N}$-type calcium channel inhibition. This uncoupling equally affects both the voltage-dependent and voltageindependent inhibitory pathways initiated by mGluR1 activation of G-protein released from $\mathrm{G} \alpha_{\mathrm{i} / \mathrm{o}}$ and from $\mathrm{G} \alpha_{\mathrm{q}}$ activation, respectively (Kammermeier et al., 2000). To determine whether addition of Homer la could rescue mGluR1 mediated $\mathrm{N}$-channel modulation, the level of Homer $2 \mathrm{~b}$ cDNA was reduced to a submaximal level, such that the average inhibition in the presence of Homer $2 b$ was approximately half of that in control cells (expressing mGluR1 alone). Finally, channel modulation was examined in cells expressing mGluR1, Homer 2b, and Homer 1a heterologously. Figure $1 A$ illustrates current traces from a test pulse to $+10 \mathrm{mV}$ and time courses of inhibition by $100 \mu \mathrm{M}$ glutamate for representative cells from each group. Clearly, this level of Homer $2 \mathrm{~b}$ expression produced a modest uncoupling from calcium channel inhibition, which was strongly recovered when Homer la was also expressed. On average, inhibition in cells expressing mGluR1 alone was $43 \pm 4 \%$ $(n=10$; average \pm SEM $)$. Inhibition was reduced to $24 \pm 6 \%$ $(n=9)$ with Homer $2 \mathrm{~b}$ coexpression and recovered to $55 \pm 3 \%$ $(n=6)$ in cells expressing mGluR1 with both Homer $2 \mathrm{~b}$ and Homer 1a (Fig. 1B). These data demonstrate that addition of Homer 1a to this system can restore coupling of mGluR1 to $\mathrm{N}$-type calcium channels in the presence of Homer $2 \mathrm{~b}$.

\section{PACAP treatment restores calcium channel modulation in Homer 2b-expressing neurons}

To begin to determine whether upregulation of endogenous Homer 1a could restore mGluR1-mediated calcium channel modulation in the presence of Homer 2b, SCG neurons were pretreated 3-5 h with $200 \mathrm{nM}$ PACAP, a PAC1 receptor agonist known to stimulate Homer 1a expression in SCG neurons (Girard et al., 2004). The level of native Homer 1a expression resulting from PACAP treatment is likely to be small compared with that attributable to overexpression, although precise levels in individual living cells (such as the relatively small number of SCG neurons used in these electrophysiological studies) are fairly intractable. Nonetheless, pretreatment with PACAP to cells did produce a modest restoration of mGluR1-mediated calcium channel modulation in Homer 2b-expressing cells (Fig. 2A). In this set of experiments, $\mathrm{N}$-channel inhibition in cells expressing mGluR 1 alone averaged $50 \pm 3 \%(n=22)$. Homer $2 \mathrm{~b}$ coexpression reduced the inhibition to $24 \pm 5 \%(n=16)$, whereas after pretreatment with PACAP it was restored to $42 \pm 5 \%(n=9)$.

To rule out direct effects of Homer $2 \mathrm{~b}$ expression and PACAP
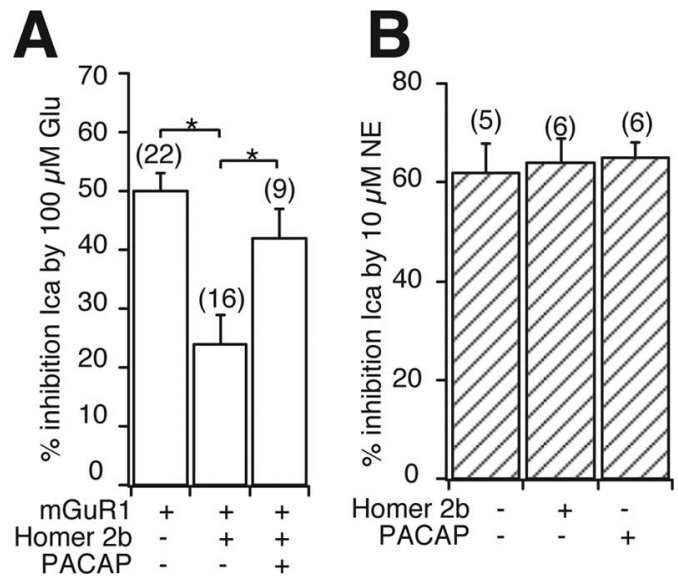

Figure 2. Homer $2 b$-induced loss of mGluR1 coupling to $\mathrm{N}$-type calcium channels is rescued by PACAP treatment. $\boldsymbol{A}$, Average \pm SEM calcium current inhibition for SCG neurons with the indicated mGluR1 and Homer $2 \mathrm{~b}$ expression, with and without pretreatment for $3-5 \mathrm{~h}$ with 200 nм PACAP. ${ }^{*} p \leq 0.05$ (ANOVA). $\boldsymbol{B}$, Average \pm SEM calcium current inhibition in response to 10 $\mu \mathrm{M}$ NE showing that neither Homer $2 \mathrm{~b}$ expression nor PACAP treatment altered this pathway. The number of cells in each group is shown in parentheses.

pretreatment to signaling intermediates or the calcium channels, inhibition in response to $10 \mu \mathrm{M}$ norepinephrine (NE) mediated by endogenous $\alpha 2$ adrenergic receptors (Schofield, 1990) was also examined. Figure $2 B$ shows that, in each condition, $\mathrm{N}$-channel modulation through this receptor was unaltered, supporting the conclusion that the observed changes in mGluR1mediated channel inhibition were specifically attributable to effects at the level of the receptor. In uninjected cells, NE inhibited the current by $62 \pm 6 \%(n=5)$. Homer $2 \mathrm{~b}$ expression and PACAP pretreatment resulted in NE-mediated inhibitions of $64 \pm 5 \%(n=6)$ and $65 \pm 3 \%(n=6)$, respectively. Together, these data suggest that stimulation of natively expressed Homer 

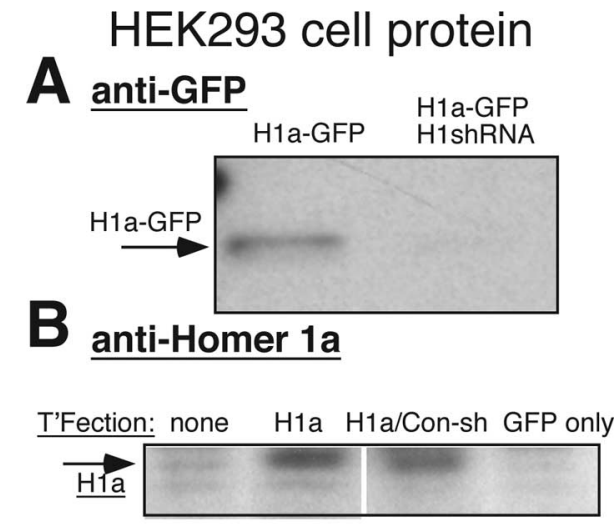

C anti-panHomer

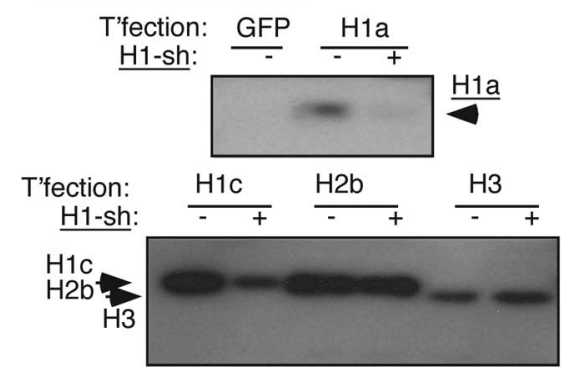

Figure 3. Homer 1 shRNA effectiveness and specificity. $\boldsymbol{A}$, Western blot showing GFP immunoreactivity of protein isolated from HEK293 cells expressing Homer 1a-GFP alone (lane 1) or Homer 1a-GFP plus H1-shRNA (lane 2). B, Western blot showing Homer 1a immunoreactivity of protein isolated from untransfected HEK293 cells (lane 1), cells expressing Homer 1a alone (lane 2), Homer 1a plus Con-shRNA (lane 3), and GFP only (lane 4). C, Western blot showing pan-Homer immunoreactivity of protein isolated from HEK293 cells expressing Homer $1 \mathrm{c}$ with or without H1-shRNA (lanes 1, 2), Homer 2b with or without H1-shRNA (lanes 3, 4), and Homer 3 with or without H1-shRNA (lanes 5,6 ).

1a can effectively promote mGluR 1 coupling to N-type calcium channels.

\section{PACAP effects on mGluR1/N-channel coupling result from Homer la expression}

Pretreatment of SCG neurons with PACAP for 3-5 h is likely to produce effects other than Homer 1a expression. Thus, it was important to verify that the restoration of mGluR1/N-channel coupling was specifically attributable to native Homer 1a expression. To achieve this, expression of Homer la protein was specifically prevented by coexpression of a targeted shRNA construct.

Several shRNA constructs were initially screened for their effectiveness in preventing Homer 1a expression in HEK293 cells. The most effective construct we identified generated 19-mer hairpins corresponding to Homer 1a RNA starting at nucleotide 155 (Fig. 3A, "H1-shRNA"). This construct reduced expression of Homer 1a-GFP to nearly undetectable levels. In addition, a number of constructs screened were ineffective at preventing or reducing Homer la expression. One of these, corresponding to a 19-mer starting at Homer 1a site 539, failed to alter Homer 1a expression in HEK293 cells (Fig. 3B, "Con-shRNA"). This construct was therefore used in subsequent experiments as a negative control shRNA. Finally, the specificity of the H1-shRNA construct was tested against other Homer protein isoforms (Fig. 3C). HEK293 cells were transfected with Homer 1a, 1c, 2b, and 3, each in the absence and presence of the H1-shRNA. Expression of both Homer 1a and 1c were reduced by the shRNA, which was expected because it targets a sequence in which both isoforms are

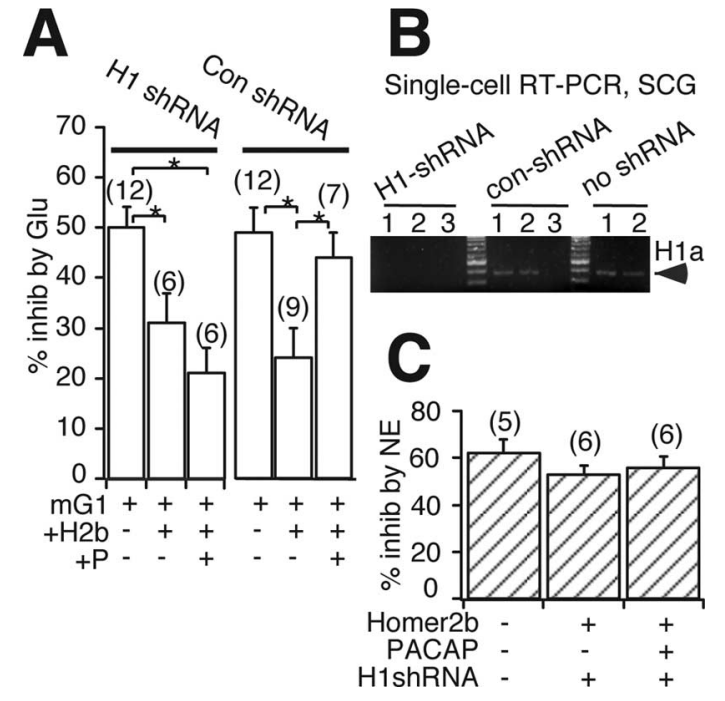

Figure 4. H1-shRNA but not Con-shRNA prevents the PACAP effect on mGluR1 coupling to calcium currents in SCG neurons expressing Homer $2 \mathrm{~b}$. $A$, Average \pm SEM calcium current inhibition for SCG neurons with the indicated mGluR1 (mG1) and Homer 2b ( $+\mathrm{H} 2 \mathrm{~b}$ ) expression, with and without pretreatment for $3-5 \mathrm{~h}$ with $200 \mathrm{~nm}$ PACAP $(+P)$, coexpressing either the specific H1-shRNA or Con-shRNA, as indicated. ${ }^{*} p \leq 0.05$ (ANOVA). $\boldsymbol{B}$, Results of single-cell RT-PCR experiment to detect Homer 1a message from individual SCG neurons expressing $\mathrm{H} 1-$ shRNA, Con-shRNA, or no shRNA, as indicated. All cells shown were pretreated with PACAP, as described in Figure 2. C, Average \pm SEM calcium current inhibition in response to $10 \mu \mathrm{M} N \mathrm{NE}$ showing that neither Homer 2b/H1-shRNA expression alone nor when pretreated with PACAP altered this pathway.

identical. Conversely, Homer $2 \mathrm{~b}$ and 3 expression were unaffected by the H1-shRNA (Fig. 3C), demonstrating specificity of the knockdown.

To determine whether stimulation of native Homer la expression was specifically responsible for the recovery of mGluR $1 / \mathrm{N}$ channel coupling in SCG neurons expressing Homer 2b, the experiments were repeated in the presence of either the effective, H1-shRNA plasmid, or the ineffective control, Con-shRNA plasmid. As the data summarized in Figure $4 A$ indicate, blocking Homer 1a expression with the H1-shRNA construct prevented the restoration of calcium channel modulation after PACAP treatment. In contrast, coinjection of the Con-shRNA construct was unable to prevent PACAP-mediated recovery of mGluR1/Nchannel coupling. Furthermore, injection of the shRNA constructs themselves had no effect on basal mGluR1 signaling (compare mGluR1 controls in Fig. $4 A$ with those in Figs. $1 \mathrm{~B}, 2 \mathrm{~A}$ ). In the presence of the coinjected $\mathrm{H} 1-$ shRNA plasmid, calcium channel inhibition by mGluR1 alone, with Homer 2b coexpression, and with Homer $2 \mathrm{~b}$ and PACAP treatment was $50 \pm 4 \%$ $(n=12), 31 \pm 6 \%(n=6)$, and $21 \pm 5 \%(n=6)$, respectively. Average inhibitions of the corresponding groups coinjected with the Con-shRNA plasmid were $49 \pm 5 \%(n=12), 24 \pm 6 \%(n=$ $9)$, and $44 \pm 5 \%(n=7)$, respectively.

Although the H1-shRNA and Con-shRNA effects were verified in HEK293 cells (Fig. 3), confirmation was sought to confirm that these constructs were working similarly in the SCG system. However, because intranuclear cDNA injection results in effective transfection of only a small handful of cells, standard immunoblotting techniques could not be used. Furthermore, available Homer antibodies are not able to distinguish between long and short Homer proteins (except by size), so immunofluorescence was also unfeasible. Therefore, single-cell reverse transcription (RT)-PCR of successfully injected cells (determined by GFP ex- 
pression from a separate plasmid) was used to detect Homer la message in SCG neurons (Fig. $4 B$ ). In four of six control cells ("no shRNA," only two of six are shown), Homer la message was detectable. Likewise, a clear band was seen in two of three samples generated from cells injected with the control shRNA ("ConshRNA," lanes 1 and 2). In contrast, no Homer la message was detectable in three SCG neurons injected with the H1shRNA. These data support the conclusion that H1-shRNA prevents Homer la expression whereas Con-shRNA does not in isolated SCG neurons.

Finally, the possibility that treatments similar to those used in the experiments described in Figure $4 \mathrm{~A}$ produced unanticipated effects on G-proteins or the calcium channels in SCG neurons, NE-mediated calcium channel inhibition was also examined (Fig. 4C). As expected, modulation by NE was unaffected by $\mathrm{H} 1$-shRNA/PACAP or by the combination of Homer $2 b$ and shRNA expression with PACAP pretreatment. These treatments resulted in NE inhibitions of $53 \pm 4 \%(n=6)$ and $56 \pm 5 \%$ $(n=6)$, respectively (the control group shown in Fig. $4 C$ is identical to the control data in Fig. $2 \mathrm{~B}$ ). Together, these data support the conclusion that the restoration of mGluR1/N-channel coupling after PACAP treatment is specifically attributable to downstream induction of Homer 1a expression. Thus, even the relatively low levels of Homer 1a that result from PACAP treatment are capable of rescuing mGluR1mediated N-channel modulation in the presence of Homer $2 \mathrm{~b}$.

\section{PACAP induces Homer 1a expression and uncouples group I} mGluRs from EPSC modulation in hippocampal neurons

To examine the ability of natively expressed Homer 1a to regulate mGluR signaling in neurons in which all the signaling components, from receptor to effector, were native to the system, mGluR5-mediated modulation of AMPA currents in cultured hippocampal autaptic neurons was examined. Unlike N-channel modulation, inhibition of AMPA currents by mGluR5 requires $\mathrm{IP}_{3}$ receptor activation (see below). Therefore, the presence of short Homer proteins should occlude this pathway rather than enhance it. In this sense, AMPA current inhibition by mGluR5 represents the opposite end of the Homer/mGluR regulatory spectrum. Thus, it is important to test not just whether endogenous Homer la can promote coupling to an $\mathrm{IP}_{3}$ receptorindependent effector (N-type calcium channels) but also whether it can reduce coupling of group I mGluRs to an $\mathrm{IP}_{3}$ receptor-dependent effector (AMPA receptors), as suggested by the predominant model.

In an autaptic system, single neurons grown on isolated " $m i-$ croislands" of substrate form synapses onto themselves ("autapses"). Thus, using patch-clamp electrophysiology, synaptic currents can be recorded after an evoked action potential volley in the distal, unclamped processes by briefly depolarizing the cells to positive voltages (Bekkers and Stevens, 1991; Kammermeier and Worley, 2007). Recently, we have shown that, in this system, under the same conditions used here, most autapses are excita- tory, i.e., exhibit EPSCs, mediated primarily by AMPA-like (nonNMDA) channels. Furthermore, application of the group I mGluR-selective agonist DHPG $(50 \mu \mathrm{M})$ for $<1$ min produces a strong, essentially reversible inhibition of the EPSC in most cells. This inhibition originates postsynaptically, is mediated by mGluR5, and requires $\mathrm{IP}_{3}$ receptor activity (Kammermeier and Worley, 2007). Finally, in contrast to the increase in coupling seen between mGluRs and N-type calcium currents in SCG neurons, overexpression of Homer 1a in hippocampal autapses decreases coupling of the native mGluR5 from AMPA receptor modulation (Kammermeier and Worley, 2007).

To determine whether stimulation of native Homer 1a could produce a similar uncoupling of mGluR5 from EPSC inhibition as overexpression of Homer la (Kammermeier and Worley, 2007), PACAP pretreatment was used to induce endogenous Homer 1a expression, as in the SCG experiments described above. PACAP treatment has been reported by other groups to induce Homer la expression in hippocampal neurons (Nielsen et al., 2002; Girard et al., 2004), and this observation was confirmed here by immunoblotting protein from control hippocampal cultures and those pretreated $4 \mathrm{~h}$ with $200 \mathrm{~nm}$ PACAP (Fig. 5C), albeit to a modest degree. PACAP treatment enhanced total Homer la levels by 2.5 -fold over untreated cells (to $250 \pm 31 \%$; $n=3$, detected by immunoblot). Even after PACAP treatment, Homer 1a levels in Western blots still appeared considerably lower than the long Homer band (data not shown). Thus, PACAP treatment upregulates Homer la expression in hippocampal neurons.

Next, EPSC inhibition in response to $50 \mu \mathrm{M}$ DHPG was examined in untreated hippocampal autapses and in those pretreated with PACAP to determine whether endogenous Homer 1a alters this response as strongly as Homer la overexpression (Kammer- 

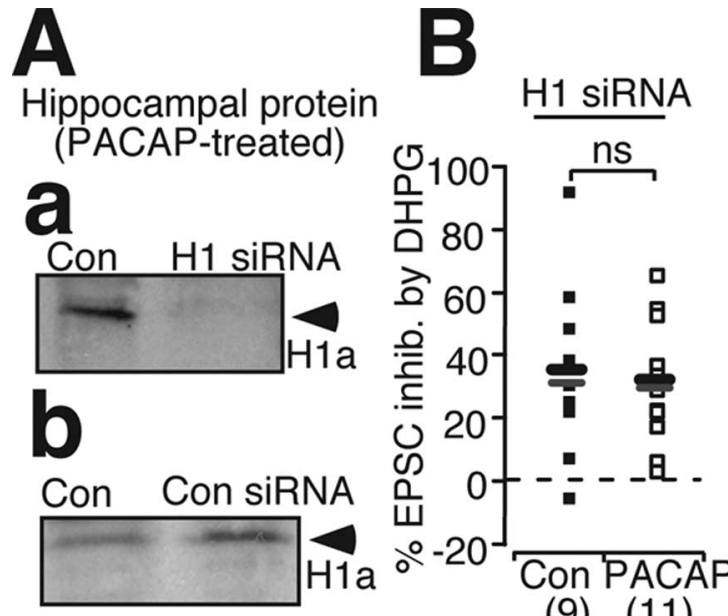

(9) (11)

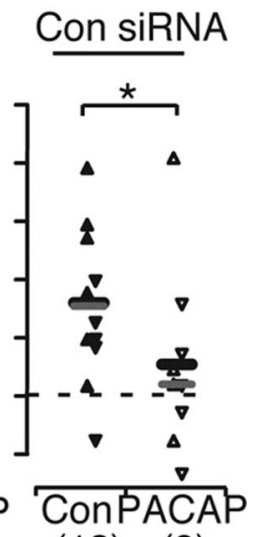

(12) (9)

Figure 6. H1-siRNA but not Con-siRNA prevents the PACAP effect on mGluR5 EPSC inhibition in hippocampal autapses. Aa, Western blot showing Homer 1a immunoreactivity of protein from control hippocampal cultures (lane 1, Control) and those transfected with H1-siRNA (lane 2, H1 siRNA) $1 \mathrm{~d}$ before protein isolation. Ab, Western blot showing Homer 1a immunoreactivity of protein from control hippocampal cultures (lane 1, Control) and those transfected with Con-siRNA (lane 2, Con siRNA) $1 \mathrm{~d}$ before protein isolation. $\boldsymbol{B}$, Scatter plot showing maximal DHPG inhibition in each autaptic neuron of each group. Left, $\mathbf{\square}$, H1-siRNA-transfected, untreated; $\square$, H1-siRNA-transfected, PACAP pretreated. Right, $\mathbf{\Delta}$, Con-siRNA-transfected, untreated; $\triangle$, Con-siRNA-transfected, PACAP pretreated; $\nabla$, Con-Cy3-siRNA-transfected, untreated; $\nabla$, Con-Cy3-siRNA-transfected, PACAP-treated. Mean (black line) and median (gray line) inhibitions are also indicated. ${ }^{*} p \leq 0.05$ ( $t$ test). ns indicates no significant difference.

meier and Worley, 2007). Similar to results reported previously, DHPG produced a strong inhibition of the EPSC in most cells tested, but with a wide scatter (Fig. 5B). Average EPSC inhibition in control cells was $41 \pm 8 \%(n=16$; median inhibition was $43 \%)$. In addition, to confirm that mGluR5 was acting postsynaptically (Kammermeier and Worley, 2007), paired stimuli were applied to these cells with an interstimulus interval of $50 \mathrm{~ms}$. This paired pulse ratio (the second response divided by the first; a reflection of neurotransmitter release) was $0.85 \pm 0.11$ before DHPG application and $1.0 \pm 0.22(n=16)$ at peak DHPG inhibition. This difference was not significant $(p>0.6)$, consistent with a postsynaptic mechanism of action.

After pretreatment with PACAP, mGluR5 inhibition of the EPSC was lost, unmasking a weak enhancement of the current in a small number of cells. In PACAP-treated cells, the average DHPG inhibition was $5 \pm 4 \%(n=12$; median inhibition was $4 \%)$. As a control for specificity of this effect, EPSC inhibition using two other agonists, the group III mGluR agonist L-AP-4 and the adrenergic agonist NE were also examined. Responses to these drugs were highly variable but did not appear to be weakened by PACAP treatment. In the absence and presence of PACAP pretreatment, respectively, $300 \mu \mathrm{M} \mathrm{L}-\mathrm{AP}-4$ inhibited the EPSC by $17 \pm 9 \%(n=4)$ and $22 \pm 6 \%(n=3)$, whereas $10 \mu \mathrm{M}$ NE inhibited the EPSC by $28 \pm 15 \%(n=4)$ and $30 \pm 14 \%(n=$ $5)$. Thus, upregulation of Homer 1a to apparently modest levels appeared to be sufficient to strongly and specifically uncouple postsynaptic mGluR5 from inhibiting the EPSC.

\section{The PACAP effect in hippocampal autapses requires Homer 1a expression}

In a set of experiments analogous to those described above with SCG neurons, RNA interference was used to prevent Homer 1a expression in response to PACAP treatment, and DHPGmediated EPSC inhibition was examined. However, because hippocampal neurons must be kept in culture for $7 \mathrm{~d}$ and high transfection efficiency was necessary, direct transfection of double-

stranded siRNA was used rather than shRNA-generating plasmids. The specific Homer 1-targeting siRNA used was a 19mer corresponding to the hairpin RNA generated by the H1-shRNA plasmid. This siRNA effectively prevented Homer la expression in PACAP-treated hippocampal neurons (Fig. 6Aa) and prevented the DHPG/EPSC uncoupling effect of PACAP (Fig. $6 B$, left). In autapses transfected with H1 siRNA, average EPSC inhibition was $35 \pm 10 \%(n=9$; median $31 \%)$ in control, untreated cells and $31 \pm 6 \%(n=11$; median 25\%) in PACAP-treated cells. In contrast, transfection with a control siRNA corresponding to the hairpin generated by the Con-shRNA described above failed to prevent Homer 1a expression (Fig. 6Ab) and did not prevent reduction in EPSC inhibition after PACAP treatment (Fig. $6 B$, right). Control siRNA-transfected autapses untreated and treated with PACAP were inhibited with DHPG by $21 \pm 8 \%$ $(n=6$; median $22 \%)$ and $3 \pm 10 \%(n=5$; median 3\%), respectively. Finally, a few autaptic neurons were transfected with a commercially available control Cy3conjugated siRNA. This control siRNA was likewise unable to prevent the PACAP-mediated reduction in DHPG-mediated EPSC inhibition. Untreated and PACAP-treated neuronal EPSCs in this group were inhibited by $41 \pm 11 \%(n=6$; median $44 \%)$ and $19 \pm 21 \%(n=4$; median $6 \%)$ with $50 \mu \mathrm{M}$ DHPG, respectively. Pooled data shown in Figure $6 B$ (right) illustrate that, in the presence of control siRNAs, PACAP treatment significantly reduced DHPG-mediated EPSC inhibition.

Together, the results described above confirm that PACAP treatment can effectively alter mGluR signaling in SCG and hippocampal neurons and that this regulation is likely attributable specifically to stimulation of natively expressed Homer 1a.

\section{Discussion}

Numerous studies using overexpression of Homer proteins have suggested a model in which group I mGluR signaling is regulated by association with either long (Homer 1b, 1c, 2, 3) or short (Homer 1a, Ania-3) Homer proteins. In short, this model suggests that long Homer proteins act as a scaffold to localize mGluR1 and mGluR5 near $\mathrm{IP}_{3}$ receptors, which facilitates coupling to $\mathrm{IP}_{3}$ receptor activation and to downstream effectors. In contrast, short Homers act as dominant negatives by competing for mGluR association but not colocalizing $\mathrm{mGluRs}$ to $\mathrm{IP}_{3}$ receptors, which promotes mGluR coupling to $\mathrm{IP}_{3}$ receptorindependent effectors such as ion channels modulated by direct G-protein binding or phosphatidylinositol-4, 5-biphosphate depletion (Thomas, 2002), such as N-type calcium and M-type potassium channels.

To date, the ability of natively expressed Homer proteins to affect mGluR signaling has not been directly tested. Here, I test this model using two neuronal systems in which regulation of group I mGluR signaling by Homer proteins has been described (Kammermeier et al., 2000; Kammermeier and Worley, 2007). In both rat SCG neurons and cultured rat hippocampal neurons, activation of the PAC1 receptor for $2-6 \mathrm{~h}$ by the peptide ligand PACAP results in elevation of Homer 1a protein levels (Girard et 
al., 2004). In SCG neurons, heterologous expression of Homer 2b uncouples mGluR1 from N-type calcium channel modulation. Here I show that this pathway is restored by both heterologous expression of Homer 1a and by PACAP pretreatment. Elevation of native Homer la mediates the restoration of this coupling by PACAP because Homer 1-specific shRNA, but not control shRNA, prevents it. Furthermore, EPSC inhibition by the group I mGluR agonist DHPG in hippocampal autapses was dramatically reduced by PACAP pretreatment, an effect that mimics Homer 1a overexpression in this system (Kammermeier and Worley, 2007). This PACAP effect was also sensitive to Homer 1 knockdown but not to control siRNA treatment. Ideally, a demonstration of enhanced DHPG coupling to calcium channels in hippocampal neurons could be shown during PACAP treatment. Unfortunately, as demonstrated recently by Kammermeier and Worley (2007), even in the absence of Homer 1a, DHPG already strongly inhibits these channels, possibly because the somatic receptors may be free of Homer proteins under basal conditions, so this experiment was not likely to yield interpretable data. Together, these results demonstrate that natively expressed Homer la, even at relatively low levels, can effectively regulate group I mGluR signaling in neurons.

A potential complication here is that the H1-sh/siRNA used can reduce Homer 1c and probably Homer $1 \mathrm{~b}$ levels in addition to preventing Homer 1a expression. However, this should not affect interpretation. Long Homer proteins, many of which are constitutively expressed in hippocampal (Brakeman et al., 1997) and SCG (Kammermeier et al., 2000) neurons, appear to act redundantly with respect to mGluR signaling (Kammermeier et al., 2000; Kammermeier, 2006). Thus, in the absence of PACAP treatment, whether Homer $1 \mathrm{~b} / \mathrm{c}$ levels are reduced or not, long Homer proteins are the predominant natively expressed isoform. Because these experiments were designed to examine mGluR signaling in untreated and PACAP-treated cells, the assumption of this point is directly tested. In both SCG and hippocampal neurons, baseline mGluR signaling is similar in the absence and presence of Homer 1 knockdown, demonstrating that the critical factor (the ratio of long/short Homer proteins) is unaltered when cells are untreated with PACAP.

A number of recent studies have implicated Homer proteins as important regulators of central mGluR signaling, including mGluR-dependent long-term depression, called mGluR-LTD (Mao et al., 2005; Van Keuren-Jensen and Cline, 2006; Ronesi and Huber, 2008; Ueta et al., 2008). However, a few important questions have persisted. For example, to what degree do Homermediated changes in mGluR1 and mGlur5 signaling underlie Homer-dependent changes in mGluR-LTD? Implicit in this question is the need to more completely resolve the mechanism of this process from receptor activation to manifested changes in synaptic strength, including not only the issue of the identity of intermediate messengers but also the potential need for structural organization between signaling intermediates. Is postsynaptic mGluR signaling necessary to induce mGluR-LTD? Do Homer proteins exert effects on downstream messengers independent of their direct effects on mGluRs? Close examination of the data from papers examining mGluR-LTD exemplifies the need for these answers. For example, in virtually every case in which mGluR-LTD is abolished by addition of Homer proteins, acute mGluR-dependent EPSP inhibition persists, although it is clearly sensitive to direct mGluR antagonists (Ronesi and Huber, 2008; Ueta et al., 2008). Although much of the data presented here are consistent with the conclusions from those studies, the issue of acute EPSP/EPSC inhibition highlights the main discrep- ancy. A more thorough mechanistic understanding should help to clarify these differences.

In the present study, I take a first step by showing that protocols (PACAP treatment) that upregulate endogenous short Homer proteins alter postsynaptic mGluR signaling at the level of the receptor and that this change is specifically attributable to the presence of Homer 1a. This confirms predictions from many overexpression studies that changes in the ratio of long to short Homer proteins can effectively, even potently, alter group I mGluR signaling. Importantly, these data show that these changes occur at Homer la levels many fold lower than those experienced in overexpression studies. It remains to be determined whether native Homer 1a is enhanced selectively at the postsynapse or in a more widespread manner, but this issue further highlights the problem of introducing recombinant Homer proteins experimentally as introduction of Homer 1a to a cell globally may produce effects in excess of native expression and unrealistic in a more physiological setting. Interestingly, selective localization could explain why apparently little Homer 1a is needed to potently redirect mGluR signaling and may give some insight into the mechanisms of more downstream mGluRmediated signaling events.

\section{References}

Bekkers JM, Stevens CF (1991) Excitatory and inhibitory autaptic currents in isolated hippocampal neurons maintained in cell culture. Proc Natl Acad Sci U S A 88:7834-7838.

Brakeman PR, Lanahan AA, O’Brien R, Roche K, Barnes CA, Huganir RL, Worley PF (1997) Homer: a protein that selectively binds metabotropic glutamate receptors. Nature 386:284-288.

Ehrengruber MU, Kato A, Inokuchi K, Hennou S (2004) Homer/Vesl proteins and their roles in CNS neurons. Mol Neurobiol 29:213-227.

Feng W, Tu J, Yang T, Vernon PS, Allen PD, Worley PF, Pessah IN (2002) Homer regulates gain of ryanodine receptor type 1 channel complex. J Biol Chem 277:44722-44730.

Girard BM, Keller ET, Schutz KC, May V, Braas KM (2004) Pituitary adenylate cyclase activating polypeptide and $\mathrm{PAC1}$ receptor signaling increase Homer la expression in central and peripheral neurons. Regul Pept 123:107-116.

Herlitze S, Garcia DE, Mackie K, Hille B, Scheuer T, Catterall WA (1996) Modulation of $\mathrm{Ca}^{2+}$ channels by G-protein bg subunits. Nature 380:258-262.

Hille B (1994) Modulation of ion channel function by G-protein coupled receptors. Trends Neurosci 17:531-536.

Ikeda SR (1996) Voltage-dependent modulation of N-type calcium channels by G-protein bg subunits. Nature 380:255-258.

Ikeda SR (1997) Heterologous expression of receptors and signaling proteins in adult mammalian sympathetic neurons by microinjection. In: Methods in molecular biology (Challis RAJ, ed), pp 191-202. Totowa, NJ: Humana.

Ikeda SR, Lovinger DM, McCool BA, Lewis DL (1995) Heterologous expression of metabotropic glutamate receptors in adult rat sympathetic neurons: subtype-specific coupling to ion channels. Neuron 14:1029-1038.

Kammermeier PJ (2006) Surface clustering of metabotropic glutamate receptor 1 induced by long Homer proteins. BMC Neurosci 7:1.

Kammermeier PJ, Ikeda SR (1999) Expression of RGS2 alters the coupling of metabotropic glutamate receptor $1 \mathrm{a}(\mathrm{mGluR} 1 \mathrm{a})$ to $\mathrm{M}$-type $\mathrm{K}^{+}$and $\mathrm{N}$-type $\mathrm{Ca}^{2+}$ channels. Neuron 22:819-829.

Kammermeier PJ, Worley PF (2007) Homer la uncouples metabotropic glutamate receptor 5 from postsynaptic effectors. Proc Natl Acad Sci U S A 104:6055-6060.

Kammermeier PJ, Xiao B, Tu JC, Worley PF, Ikeda SR (2000) Homer proteins regulate coupling of group I metabotropic glutamate receptors to N-type calcium and M-type potassium channels. J Neurosci 20:7238-7245.

Mao L, Yang L, Tang Q, Samdani S, Zhang G, Wang JQ (2005) The scaffold protein Homer 1b/c links metabotropic glutamate receptor 5 to extracel- 
lular signal-regulated protein kinase cascades in neurons. J Neurosci 25:2741-2752.

Nielsen HS, Georg B, Hannibal J, Fahrenkrug J (2002) Homer-1 mRNA in the rat suprachiasmatic nucleus is regulated differentially by the retinohypothalamic tract transmitters pituitary adenylate cyclase activating polypeptide and glutamate at time points where light phase-shifts the endogenous rhythm. Brain Res Mol Brain Res 105:79-85.

Ozawa S, Kamiya H, Tsuzuki K (1998) Glutamate receptors in the mammalian central nervous system. Prog Neurobiol 54:581-618.

Ronesi JA, Huber KM (2008) Homer interactions are necessary for metabotropic glutamate receptor-induced long-term depression and translational activation. J Neurosci 28:543-547.

Schoepp DD (2001) Unveiling the functions of presynaptic metabotropic glutamate receptors in the central nervous system. J Pharmacol Exp Ther 299:12-20.

Schofield GG (1990) Norepinephrine blocks a calcium current of adult rat sympathetic neurons via an $\mathrm{a}_{2}$-adrenoceptor. Eur J Pharmacol 180:37-47.

Suh BC, Hille B (2002) Recovery from muscarinic modulation of m current channels requires phosphatidylinositol 4,5-bisphosphate synthesis. Neuron 35:507-520.

Thomas U (2002) Modulation of synaptic signalling complexes by Homer proteins. J Neurochem 81:407-413.
Tu JC, Xiao B, Yuan JP, Lanahan AA, Leoffert K, Li M, Linden DJ, Worley PF (1998) Homer binds a novel proline-rich motif and links group 1 metabotropic glutamate receptors with $\mathrm{IP}_{3}$ receptors. Neuron 21:717-726.

Tu JC, Xiao B, Naisbitt S, Yuan JP, Petralia RS, Brakeman P, Doan A, Aakalu VK, Lanahan AA, Sheng M, Worley PF (1999) Coupling of mGluR/ Homer and PSD-95 complexes by the shank family of postsynaptic density proteins. Neuron 23:583-592.

Ueta Y, Yamamoto R, Sugiura S, Inokuchi K, Kato N (2008) Homer 1a suppresses neocortex long-term depression in a cortical layer-specific manner. J Neurophysiol 99:950-957.

Van Keuren-Jensen K, Cline HT (2006) Visual experience regulates metabotropic glutamate receptor-mediated plasticity of AMPA receptor synaptic transmission by homerla induction. J Neurosci 26:7575-7580.

Xiao B, Tu JC, Petralia RS, Yuan JP, Doan A, Breder CD, Ruggiero A, Lanahan AA, Wenthold RJ, Worley PF (1998) Homer regulates the association of group 1 metabotropic glutamate receptors with multivalent complexes of homer-related, synaptic proteins. Neuron 21:707-716.

Yuan JP, Kiselyov K, Shin DM, Chen J, Shcheynikov N, Kang SH, Dehoff MH, Schwarz MK, Seeburg PH, Muallem S, Worley PF (2003) Homer binds TRPC family channels and is required for gating of TRPC1 by $\mathrm{IP}_{3}$ receptors. Cell 114:777-789. 